\title{
Corneal transplantation: how successful are we?
}

The cornea is one of a few relatively immunologically privileged sites within the human body. ${ }^{1}$ Corneal transplant surgery is the most commonly performed allograft in the United Kingdom. ${ }^{2}$ In terms of solid tissue allografts in humans, the cornea appears to be very successful with an overall first year survival rate as high as $90 \% .^{3}$ Unfortunately, the long term reality is that the overall success rate diminishes to $74 \%$ at 5 years and $62 \%$ at 10 years ${ }^{3}$ (Fig 1 ). In those eyes considered to be "high risk", especially those with corneal neovascularisation or ongoing ocular inflammation, the long term 10 year survival rate is less than $35 \%{ }^{4}$ (Fig 1). Of greater concern is that these survival rates have not improved over the past 10 years. ${ }^{5}$

The leading cause of corneal transplant failure is allograft rejection. ${ }^{56}$ Table 1 illustrates the causes of corneal graft failure using data from the Australian Corneal Graft Registry (ACGR) ${ }^{5}$ and the Corneal Transplant Follow-up Study (CTFS). ${ }^{6}$ As one third of failures are due to irreversible rejection episodes, are ophthalmologists being unduly complacent about the management of such events? Furthermore, is this disappointingly poor and non-improving long term outcome seen with other solid organ transplants?

A review of the United Kingdom Transplant Support Service Authority (UKTSSA) audit data for the 1985-95 time period illustrates the following survival rates. For heart transplantation, the overall survival rate at 1 year was $75 \%$, falling to $64 \%$ at 5 years. ${ }^{7}$ The 12 month transplant survival rate has improved from $73 \%$ to $77 \%$ between the first and second 5 year periods of the 10 year audit review. ${ }^{7}$ Liver transplantation was less successful with overall 1 year and 5 year survival rates of $65 \%$ and $55 \%$ respectively, diminishing to $44 \%$ at 10 years $^{8}$ (Fig 1). Nevertheless, the 1 year and 5 year survival rates dramatically improved from $51 \%$ and $40 \%$ in the $1985-6$ cohort to $68 \%$ and $60 \%$ in the $1991-2$ cohort. $^{8}$ This trend has continued with a $72 \%$ one year survival rate for the 1993-4 cohort. ${ }^{8}$

The most successful solid organ transplant is the kidney, which has similar overall survival rates to the relatively immunologically privileged cornea. The 1 year survival rate for the 1984-93 time period was $92 \%$, only falling to $86 \%$ at 3 years and $80 \%$ at 5 years. The 10 year survival rate was $63 \%$ (95\% confidence interval of $61 \%$ to $66 \%)^{9}$

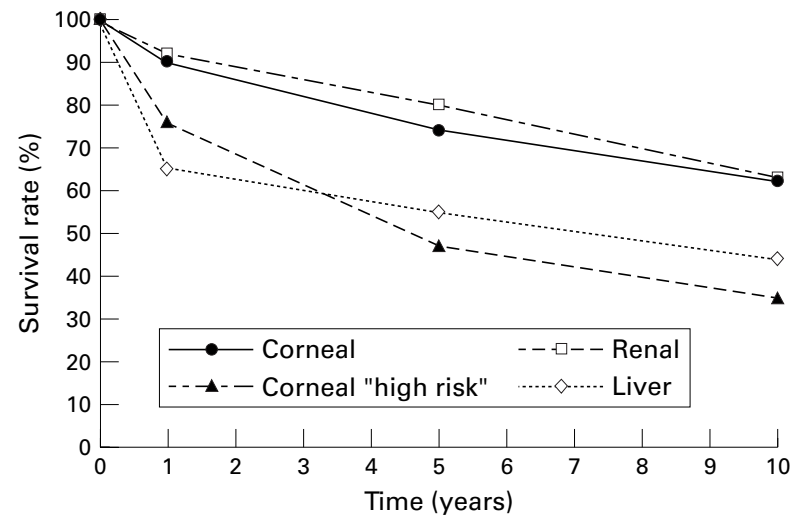

Figure 1 Comparison of organ transplant survival rates over the same time period 1984 to 1996.
Table 1 Causes of corneal transplant failure

\begin{tabular}{llll}
\hline Cause of failure & ACGR & CTFS & Combined data \\
\hline "Classic" rejection & $32 \%$ & $34 \%$ & $32 \%$ \\
Endothelial decompensation & $20 \%$ & $17 \%$ & $20 \%$ \\
Infection & $14 \%$ & $12 \%$ & $14 \%$ \\
Primary technical & $6 \%$ & $13 \%$ & $7 \%$ \\
Glaucoma & $8 \%$ & $0 \%$ & $6 \%$ \\
Disease recurrence & $0 \%$ & $7 \%$ & $1 \%$ \\
Others/unknown & $20 \%$ & $17 \%$ & $20 \%$ \\
Number in series & 985 & 201 & 1186 \\
\hline
\end{tabular}

(Fig 1). This short and medium term survival rate has been sustained from the 1984-6 cohort to the 1990-3 cohort, despite an increase in the number of renal transplants by $50 \%$ to over 4300 during the latter period.

The data from the ACGR report ${ }^{3-5}$ and the UKTSSA ${ }^{7-9}$ highlight several important issues. Firstly, a lack of information on the outcome of UK corneal transplants beyond 18 months prevents a direct comparison with the Australian data. Secondly, for a relatively immunologically privileged site, the overall long term corneal transplant survival rates are only just comparable with those of the vascularised kidney (Fig 1). Thirdly, all other solid organ transplants have demonstrated improvements in survival rates over the past 10-15 years, unlike the cornea. Fourthly, for a similar period in time, "high risk" corneal transplantation survival rates are poor (Fig 1). So are there lessons to be learnt from those performing other forms of organ transplantation? Why do corneal allografts undergo immunological rejection episodes and fail, whereas other solid organ transplants survive long term in ever increasing numbers? Is the improved outcome in solid organ surgery the result of the use of appropriate immunosuppression, or are other factors such as tissue matching and transplantation by subspecialist surgeons playing a part in long term success?

As in other fields of transplantation, the knowledge of corneal graft rejection immunology has advanced at a phenomenal rate over the past 15 years. The major histocompatibility (MHC) molecules, both major or class I antigens (HLA-A and HLA-B) and minor or class II antigens (HLA-DR), have important parts to play in transplant immunology and rejection episodes. ${ }^{10}$ HLA class I antigens are expressed in abundance on corneal epithelial, stromal, and endothelial cells, ${ }^{11}$ while there is a relatively low indigenous expression of MHC class II molecules within the cornea, either on Langerhans cells in the epithelium or dendritic cells present within the stroma. ${ }^{12}$

Early studies ${ }^{13-15}$ demonstrated a beneficial effect for HLA class I matching in the survival of corneal grafts, especially in high risk eyes. In one institution, long term 15 year survival rates of $80 \%$ were documented for high risk eyes matched for two or more HLA class I antigens. ${ }^{15}$ The effects of class II matching have remained more controversial. One group has reported a significant positive effect for HLA-DR matching in high risk eyes, citing a $79 \%$ long term survival rate. ${ }^{16}$ On the other hand, the UK based CTFS demonstrated an adverse effect in graft survival with HLA-DR matching. ${ }^{14}{ }^{17}$ A third study, the prospective multicentred American Collaborative Corneal Transplant Studies (CCTS), ${ }^{18}$ has complicated the issue by not 
finding any beneficial or adverse effects for HLA matching, whether it be class I or class II antigens. The use of an intensive postoperative topical immunosuppressive regimen achieved a $65 \%$ three year survival rate, but probably prevented any effects of HLA matching from being observed. Despite the heterogeneity of these data, a metaanalysis of these comparatively small studies suggests a beneficial effect of MHC class II mismatching in high risk eyes, but only if the CCTS data are excluded. ${ }^{19}$

The importance of HLA matching and its effect on transplant survival has been demonstrated with other organs. In renal transplantation, the greatest success rate occurs with complete HLA class II (HLA-DR) matching $^{20-22}$ and this appears to extend into long term survival rates. ${ }^{21} 23$ The UKTSSA audit data for renal transplantation ${ }^{24}$ provide an in-depth analysis of HLA mismatches and their effects on graft survival. All cases of mismatching, whether MHC class I or II antigens, have adverse effects on graft survival. An additive effect is observed on the number of mismatches at each locus, with the most significant risk for failure being associated with the number of HLA-DR mismatches. A single HLA-DR mismatch has a significant 1.16 times increased risk of graft failure, increasing to 1.36 times for two HLA-DR mismatches. ${ }^{24}$ The effect on graft survival does not appear to be limited to the first 3 months, but extends into the medium to long term, especially with two HLA-DR mismatches. ${ }^{24}$

A similar influence of positive HLA matching on heart transplantation survival rates has been demonstrated in a large collaborative study. ${ }^{25}$ More recently, there has been a greater focus on HLA-DR matching. There appear to be significant short term advantages in graft survival and greater survival rates at 1 year with good HLA-DR matching compared with HLA-A or HLA-B matching. ${ }^{26}$ In liver transplantation, the effects of HLA matching are still uncertain. ${ }^{27}$ There is some evidence to suggest that positive crossmatching may have an adverse effect on graft outcome in the short term, ${ }^{28}{ }^{29}$ although further analysis involving greater numbers of transplants is awaited to confirm these findings.

The evidence from other solid organ transplantation suggests that HLA matching should have implications for long term graft survival rates, although the numbers of transplants evaluated in these studies are large when compared with the corneal data (Table 2). Perhaps this explains the lack of a significant effect in corneal transplantation, or has the CCTS ${ }^{18}$ undermined the influence of HLA matching? The only real mechanism for clarifying the situation is to await the evidence from longer and larger prospective studies evaluating the role of HLA matching on corneal graft survival.

HLA matching represents one aspect of corneal transplantation immunology that needs to be addressed. In recent years, there has been a dramatic insight in demonstrating that the cornea is active in the maintenance of its relative immune privileged status. ${ }^{30}$ Several immunological mechanisms have been demonstrated in mouse

Table 2 Comparison of number of transplants evaluated in a variety of studies

\begin{tabular}{|c|c|c|c|c|}
\hline Study & Tissue & Matching & Cohort & $\begin{array}{l}\text { Number of } \\
\text { transplants }\end{array}$ \\
\hline Stark et al (CCTS $)^{18}$ & Cornea & DR & $1986-7$ & 419 \\
\hline Baggesen et $_{a l^{16}}$ & Cornea & $\mathrm{DR}$ & $1988-90$ & 51 \\
\hline Bradley et al (CTFS) $)^{17}$ & Cornea & DR & $1987-91$ & 542 \\
\hline Opelz $^{21}$ & Kidney & $\begin{array}{l}\mathrm{DR} \\
\mathrm{A}, \mathrm{B} \text {, and }\end{array}$ & $1988-91$ & 3455 \\
\hline UKTSSA $^{24}$ & Kidney & $\begin{array}{c}\mathrm{DR} \\
\mathrm{A}, \mathrm{B} \text {, and }\end{array}$ & $1984-93$ & 10804 \\
\hline Opelz and Wujciak ${ }^{25}$ & Heart & DR & 1985-92 & 8331 \\
\hline
\end{tabular}

models suggesting the cornea participates in active immunomodulation. This includes the active expression of immunomodulatory cytokines such as interleukin $1 \mathrm{a},{ }^{31}$ a chemoattractant for Langerhans cells, ${ }^{32}$ which arguably act as the antigen presenting cell (APC) in the corneal graft rejection process. The topical application of interleukin $1 \mathrm{a}$ receptor antibody could potentially prevent the migration of Langerhans cells from the host into the donor tissue, thereby reducing the recognition by $\mathrm{T}$ cells through the indirect pathway. $^{33}$ Other studies have outlined the importance of the expression of cell surface inhibitors of immune effectors such as the Fas and Fas ligand. ${ }^{34}$ These molecules are implicated in the process of immune tolerance by causing $\mathrm{T}$ cell apoptosis. ${ }^{35}$ Subsequently, a lack of expression of the Fas ligand on the corneal endothelium can result in a greater risk of rejection. ${ }^{36} \mathrm{~A}$ mechanism that stimulates the expression of this molecular complex may assist in preventing corneal graft rejection via immune tolerance. ${ }^{36}$ Another important mechanism is the concept of anterior chamber associated immune deviation (ACAID) ${ }^{37}$ It has been shown that antigens in the anterior chamber are detected by indigenous APCs. These pass into the general circulation via the trabecular meshwork and are carried to the spleen, thereby initiating an immune response lacking both $\mathrm{T}$ cell mediated delayed hypersensitivity and B cells secreting complement fixing antibodies. ${ }^{38}$ Instead regulatory cytotoxic $\mathrm{T}$ cells and non-complement fixing antibodies are activated, creating a situation in which any inflammatory related immunogenic response is suppressed. ${ }^{38}$ An activation of this mechanism before the exposure to a donor graft may prolong graft survival. ${ }^{30}{ }^{39}$

One other potentially significant factor has also been alluded to in the 1996 ACGR. $^{40}$ In the analysis of patients undergoing corneal transplantation for keratoconus, surgeons performing more than 50 grafts per year retained a $98 \%$ nine year survival rate, compared with $86 \%$ for those performing fewer than 25 grafts per year $(p=0.003)$. Although the ability to manage the grafts in the postoperative period may partly account for this observation, there is undoubtedly an element reflecting the operative skill of the surgeon. As a consequence of "no stitch" phacoemulsification cataract surgery, the suturing skills of future ophthalmologists may not be as refined as those of ophthalmologists in the past. There may be a need to consider the role of the subspecialist corneal surgeon within each ophthalmic unit.

A reappraisal of the current situation is required. The acquisition of comparable data for other forms of transplantation occurring within the UK would be very beneficial for audit purposes. A clarification of the relevance and importance of the HLA antigens is essential. By utilising DNA tissue typing techniques ${ }^{41} 42$ for HLA matching, current studies will hopefully resolve this issue in corneal transplantation. The advances in our understanding of corneal rejection immunology in the mouse need to be confirmed in the human. This knowledge needs to be applied in conjunction with the clinical evaluation of more specific therapeutic agents that modulate the immunological mechanisms of corneal graft rejection. ${ }^{43-47}$ Finally, as with other disciplines within our specialty, such as vitreoretinal surgery, long term success may be better achieved by limiting corneal transplantation to subspecialist surgeons. By addressing these issues, it may be possible to improve overall corneal transplant survival rates by $5-10 \%$ per year and achieve better long term success with allografts in high risk vascularised corneas.

The authors thank Dr John Armitage and Dr Julie Crewe for their helpful discussion regarding the immunological aspects of this commentary. The authors also thank the Australian Corneal Graft Registry and the Corneal Transplant 

Follow up Study for giving permission to use the data which have been summa-
rised in Table 1 .

\section{A WALDOCK}

$S$ D COOK

Bristol Eye Hospital, Lower Maudlin Street, Bristol BS1 2LX

\section{Correspondence to: $\mathrm{Mr}$ A Waldock}

awaldock@hotmail.com

1 Barker CF, Billingham RE. Immunologically priviliged sites. Adv Immunol 1977;25:1-54.

2 United Kingdom Transplant Support Service Authority Transplant Update 1999. Bristol, 1999.

3 Williams KA, Muehlberg SM, Lewis RF, et al. The Australian corneal graft registry 1996 report. Adelaide: Mercury Press, 1997:11.

4 Williams KA, Muehlberg SM, Lewis RF, et al. The Australian corneal graft registry 1996 report. Adelaide: Mercury Press, 1997:47-50.

5 Williams KA, Muehlberg SM, Lewis RF, et al. The Australian corneal graft registry 1996 report. Adelaide: Mercury Press, 1997:19.

6 Vail A, Gore SM, Bradley BA, et al. Corneal graft survival and visual outcome: a multicentre study. Ophthalmology 1994;101:120-7.

7 United Kingdom Transplant Support Service Authority Cardiothoracic Organ Transplant Audit 1985-1995. Bristol, 1996:50-6.

8 United Kingdom Transplant Support Service Authority Liver Transplant Audit 1985-1995. Bristol, 1997:21-31.

9 United Kingdom Transplant Support Service Authority Renal Transplant Audit 1984-1993. Bristol, 1995:35-49.

10 Taylor CJ, Dyer PA. Histocompatibility antigens. Eye 1995;9:173-9.

11 Treseler PA, Foulks GN, Sanfilippo F. The expression of HLA antigens by cells in the human cornea. Am f Ophthalmol 1984;98:763-72.

12 McCallum RM, Cobo LM, Haynes BF. Analysis of corneal and conjunctival microenvironments using monoclonal antibodies. Invest Ophthalmol Vis Sci 1993;34:1793-803.

13 Sanfilippo F, MacQueen JM, Vaughn WK, et al. Reduced graft rejection with good HLA-A and B matching in high-risk corneal transplantation. $N$ Engl f Med 1986;315:29-35.

14 Vail A, Gore SM, Bradley BA, et al. Influence of donor and histocompatibility factors on corneal graft outcome. Transplantation 1994;58:1210-16.

15 D'Amaro J, Volker-Dieben HM, Kruit PI, et al. HLA matching and other factors in corneal transplantation: a single centre experience with more than 1800 consecutive transplants in 15 years: In: Tsuji K, Aizawa M, Sasazuki T, eds. HLA-1991. Proceedings of the eleventh international histocompatibility workshop and conference. Vol 2. Oxford: Oxford University Press, 1991:478-9.

16 Baggesen K, Lamm LU, Ehlers N. Significant effect of high-resolution HLA-DRB1 matching in high-risk corneal transplantation. Transplantation 1996;62:1273-7.

17 Bradley BA, Vail A, Gore SM et al, on behalf of the Corneal Transplant Follow-up Study collaborators. Negative effect of HLA-DR matching on Follow-up Study collaborators. Negative effect of HLA-DR
corneal transplant rejection. Transplant Proc 1995;27:1392-4.

18 Stark WJ, Stulting RD, Bias WB, et al. The Collaborative Corneal Transplantation Studies (CCTS): effectiveness of histocompatibility
matching in high-risk corneal transplantation. Arch Ophthalmol 1992;110: matching in

19 Gore SM, Vail A, Bradley BA, et al on behalf of the Corneal Transplant Follow-up Study collaborators. HLA-DR matching in corneal transplantation: systematic review of published evidence. Transplantation 1995;60:1033-9.

20 Opelz G. HLA matching should be utilised for improving kidney transplant success rates. Transplant Proc 1991;23:46-50.

21 Opelz G. Strength of HLA-A, HLA-B and HLA-DR mismatches in relation to short- and long-term kidney graft survival. Transplant Int 1992: 5(Suppl):621-4.
22 Suthanthiran M, Strom TB. Renal Transplantation. N Engl F Med 1994;331: $365-76$.

23 Suciu-Foca N, Cohen DJ, Benvenisty AI, et al. Influence of HLA matching on kidney allograft survival. Transplant Proc 1996;28:121-2.

24 United Kingdom Transplant Support Service Authority Renal Transplant Audit 1984-1993. Bristol, 1995:56-63.

25 Opelz G, Wujciak T. The influence of HLA compatibility on graft survival after heart transplantaton. N Engl F Med 1994;330:816-19.

26 Leivestad T, Foerster A, Simonsen S, et al. HLA-DR matching reduces rejection rate in heart transplantation. Transplant Int 1996;9(Suppl):2303.

27 Donaldson PT, Williams R. Cross-matching in liver transplantation. Transplantation 1997;63:789-94.

28 Charco R, Vargas V, Balsells J, et al. Influence of anti-HLA antibodies and positive T-lymphocytotoxic crossmatch on survival and graft rejection in human liver transplantation. F Hepatol 1996;24:452-9.

29 Hathaway M, Gunson BK, Keogh AC, et al. A positive crossmatch in liver transplantation - no effect or inappropriate analysis? A prospective study. transplantation - no effect or in
Transplantation 1997;64:54-9.

30 Streilein JW, Yamada J, Dana MR, et al. Anterior chamber-associated immune deviation, ocular immune privilege and orthotopic corneal immune deviation, ocular immune privile
allografts. Transplant Proc 1999;31:1472-5.

31 Kennedy MC, Rosenbaum JT, Brown J, et al. Novel production of interleukin-1 receptor antagonist peptides in normal human cornea. $\mathcal{F}$ Clin Invest 1995;95:82-8.

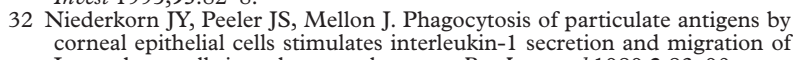
Langerhans cells into the central cornea. Reg Immunol 1989;2:83-90.

33 Yamada J, Dana MR, Zhu S-N, et al. Interleukin 1 receptor antagonist suppresses allosensitization in corneal transplantation. Arch Ophthalmol 1998; 116:1351-7.

34 Bellgrau D, Gold D, Selawry H, et al. A role for CD95 ligand in preventing graft rejection. Nature 1995;377:630-2.

35 Griffith TS, Brunner T, Fletcher SM, et al. Fas ligand-induced apoptosis as a mechanism of immune privilege. Science 1995;270:1189-92.

36 Stuart PM, Griffith TS, Usui N, et al. CD95 ligand (FasL)-induced apoptosis is necessary for corneal allograft survival. FClin Invest 1997;99:396-402.

37 Streilein JW. Anterior chamber-associated immune deviation: the privilege of immunity in the eye. Surv Ophthalmol 1990;35:67-73.

38 Niederkorn JY, Streilein JW. Alloantigens placed into the anterior chamber of the eye induce specific suppression of delayed type hypersensitivity but normal cytotoxic T lymphocyte responses. F Immunol 1983;131:2670-4.

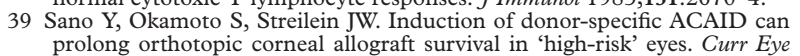
Res 1997;16:1171-4.

40 Williams KA, Muehlberg SM, Lewis RF, et al. The Australian corneal graft registry 1996 report. Adelaide: Mercury Press, 1997:17-18.

41 Bidwell JL, Bidwell EA, Savage DA, et al. A DNA-RFLP typing system that positively identifies serologically well-defined and ill-defined HLA-DR and DQ alleles, including DRw10. Transplantation 1988;3:640.

42 Olerup O, Zetterquist H. HLA-DR typing by PCR amplification with sequence specific primers (PCR-SSP) in 2 hours: an alternative to serological DR typing in clinical practice including donor-recipient matching in cadaveric renal transplantation. Tissue Antigens 1992;39:225-35.

43 Hill JC. Systemic cyclosporin in high-risk keratoplasties: short- versus longterm therapy. Ophthalmology 1994;101:128-33.

44 Olsen TW, Gothard TW, Holland EJ. Misoprostol with cyclosporin A prolongs corneal allograft survival in an animal model. Cornea 1996;15:76-81.

45 Hikita N, Lopez JS, Chan C-C, et al. Use of topical FK506 in a corneal graft rejection model in Lewis rats. Invest Ophthalmol Vis Sci 1997;38:901-9.

46 Lam DSC, Wong AKK, Tham CCY, et al. The use of combined intravenous pulse methylprednisolone and oral cyclosporin A in the treatment of corneal graft rejection: a preliminary study. Eye 1998;12:615-18.

47 Gebhardt BM, Hodkin M, Varnell ED, et al. Protection of corneal allografts by CTLA4-Ig. Cornea 1999;18:314-20. 